\title{
TEATRO DE AYER Y DE HOY A ESCENA
}

\author{
José ROMERA CASTILLO
}

(Madrid: Editorial Verbum, 2020, 439 págs.)

El último libro de José Romera Castillo, profesor emérito y catedrático de Literatura Española de la UNED, es, a la vez, guía o mapa para investigadores y teatreros, crítica teatral, estudio bibliográfico, y también filológico, por momentos, y ventana al panorama cultural y escénico más reciente de España. El propio título del trabajo manifiesta el propósito de llevar a cabo "el estudio de lo teatral tanto desde el punto de vista textual (literario) como, especialmente, desde la óptica espectacular" (p. 18). A lo largo de dieciocho capítulos, el autor analiza temas diversos, de diferentes épocas, con mayor o menor profundidad, apoyándose siempre en los estudios de las investigaciones y seminarios del SELITEN@T, o el Centro de investigación de Semiótica Literaria, Teatral y Nuevas Tecnologías de la UNED, donde también se enmarca este trabajo.

Como suele ser habitual, se dedica un prólogo general ("Prolegómenos") a la historia del SELITEN@T — fundado y dirigido por él-y sus publicaciones, para luego distribuir los recursos mencionados, la mayoría disponibles en su página web, en los capítulos o periodos correspondiente. Se menciona, en los prolegómenos, la intención de recoger la situación del teatro actual en España, a modo casi de crónica, así como los factores que influyen y forman parte de su desarrollo, como son el cine, la televisión o las nuevas tecnologías y, en resumidas cuentas, la presencia del teatro en estos medios, y viceversa. En esta apertura, destaca especialmente la intención de prestar atención y adentrarse en la puesta en escena, siempre y cuando esto resulte posible, utilizando carteleras en periódicos o revistas, entrevistas, críticas o materiales gráficos o audiovisuales, especialmente la grabación, que, por suerte, cada vez son más frecuentes en los estudios teatrales. En este sentido, este volumen se une a las publicaciones de Manuel Muñoz Carabantes, Purificació 
Mascarell, Duncan Wheeler, Carey Kasten, María Fernández Ferreiro, María Bastianes, Sergio Adillo, Mariano de Paco o David Rodríguez Solás, entre otros, muchos de los cuales han participado en alguna de las actividades o publicado con el SELITEN@T y/o la revista Signa también dirigida por el mencionado profesor-.

La labor de Romera Castillo y su equipo, que el propio autor asocia a la tarea de AITS21, la Academia de las Artes Escénicas de España, el TC/12 o el ITEM, no se reduce al elitismo académico. Por el contrario, ha existido y existe una continua preocupación por colaborar, reunirse $\mathrm{e}$ incluir en sus seminarios y actas a profesionales del teatro y artistas del ámbito, publicando incluso sus textos u obras, superando la separación que, por desgracia, sigue dándose, de vez en cuando, entre estos colectivos, y propiciando intercambios que solo pueden enriquecernos. Por otro lado, merece especial reconocimiento el esfuerzo por abarcar no solo diversas épocas y tendencias, sino también diversos lugares y espacios teatrales. Muchos estudios que ha dirigido Romera Castillo se centran en lo nacional o lo local, es decir, reconstruyen la vida escénica de una ciudad española específica. No obstante, este volumen no ignora lo que sucede en el extranjero, ya que incluye datos sobre la presencia de los clásicos españoles en Los Ángeles, por poner un ejemplo.

Las palabras de Lorca sobre el teatro sirven de epígrafe a este volumen, lo cual es, sin duda alguna, una declaración de amor a este arte. El autor decide comenzar con dos capítulos que ya nos sumergen en temas de gran actualidad. En primer lugar, hace un recorrido por la trayectoria del SELITEN@T para ofrecernos una visión panorámica de los autores y obras del teatro áureo representados entre la segunda mitad del siglo XIX y los inicios del XXI, sobre todo a partir de los trabajos, entre otros, realizados bajo su dirección, de Valeria María Rita Lo Porto y Anita Viola, basados en la cartelera del periódico $A B C$. Esta visión panorámica se complementará con el comentario a obras muy recientes, del 2013 en adelante, en el capítulo 7.

Cercano al tema es el segundo capítulo, que se centra en estudiar el teatro producido en torno a la figura y la obra de Cervantes, especialmente durante el IV centenario de su muerte en el año 2016, y, aunque no sea del todo preciso, también de la muerte de Shakespeare. El autor analiza las obras precursoras a este momento, concretamente las que se representaron en el año 2005 con motivo del IV centenario de la primera edición del 
Quijote, de Els Joglars, la Compañía Nacional de Teatro Clásico, la Joven Compañía de Teatro Clásico o Ron Lalá. Asimismo, identifica la coproducción como tendencia destacada y concluye comentando el Hamlet del Teatro Kamikaze, dirigido por Miguel del Arco, y la reposición de los Entremeses del Teatro La Abadía. Se trata de un resumen artístico de la efeméride y de la proliferación de obras que supuso, en que el autor asume el papel de historiador, e incluso de crítico, y se arriesga a afirmar que ciertos espectáculos, aprovechando las subvenciones, seguramente, se limitaban a ofrecer "adaptaciones o conglomerados con visiones poco ortodoxas” (p. 89). El capítulo 10 desarrollará en más detalle la puesta en escena y diseminación de mitos españoles como el Don Juan o la Celestina por la CNTC y en Europa, especialmente en los festivales franceses.

Los siguientes capítulos, agrupados en orden más o menos cronológico, del siglo XIX al XXI, exploran el panorama teatral de Portugal, el teatro histórico y las obras basadas en las figuras de Fernán González y de Guzmán el Bueno, con "aliento patriótico de diverso signo" (p. 135); de ahí, el autor pasa a analizar, en su faceta más filológica, la figura del trovador enamorado medieval en la obra de Antonio García Gutiérrez y la ópera de Giuseppe Verdi, ambas de la segunda mitad del siglo XIX, y, posteriormente, se detiene a comentar las dramaturgias femeninas, tanto obras escritas por mujeres como protagonizadas por personajes femeninos, comenzando por Pingüinas, de Fernando Arrabal, y Femenino plural, de Ainhoa Amestoy, ambas obras de temática cervantina, ya mencionadas en el segundo capítulo de este volumen. Esta tarea se enmarca dentro del proyecto europeo DRAMATURGAE, constituido por iniciativa del propio profesor Romera Castillo, que generó tres seminarios, y la publicación de sus actas correspondientes, en la UNED, la Université de ToulousseLe Mirail y la Universidad de Giessen. La tarea de visibilización de las dramaturgias femeninas, desde las dramaturgas consagradas, como Laila Ripoll y Angélica Liddell, hasta el trabajo con Santa Teresa de María Folguera, se desarrollará más a fondo en los capítulos 12 y 13, el último dedicado a las dramaturgas argentinas estudiadas en el SELITEN@T.

El foco en las dramaturgias femeninas se amplía con los estudios sobre los creadores teatrales más jóvenes, después de Sergi Belbel y compañía, dentro del capítulo 7. Muy interesante el análisis de la obra Grooming, de Paco Bezerra, en el capítulo 8, aprovechando la combinación de lo que Romera Castillo denomina "espacios mediáticos". Además, el 
capítulo 7 recoge apartados, que coinciden con las actas publicadas por él en Visor Libros, sobre la relación del teatro con el cine, la televisión y las nuevas tecnologías, el teatro autobiográfico, el teatro de humor, los monólogos, teatro y erotismo, y teatro y música, incluido un análisis de los musicales en lo que se ha llamado el Broadway hispanohablante (en la Gran Vía de Madrid), donde no falta El Rey León, entre otros éxitos recientes de la cartelera, del año 2013, para ser más concretos. A estos, es preciso añadir los volúmenes monográficos sobre teatro y memoria, teatro y filosofía y, por último, teatro y deporte, tema del seminario que tenía que haberse llevado a cabo este junio de 2020 y que esperemos tenga lugar en un futuro no muy lejano. Algunos de estos temas se desarrollarán más a fondo en capítulos posteriores, como es el caso de teatro y erotismo (capítulo 15) o los musicales (capítulo 17).

Más allá de los musicales, el tema de teatro y música es recurrente entre los diferentes capítulos de este volumen, desde la música en los espectáculos de Ron Lalá hasta el capítulo 16 sobre los recitales acompañados de música basados en poemas de Antonio Gala o el teatro musical del mismo autor, del que Romera Castillo es experto. Los capítulos 8 y 9 se adentran en la sonoturgia, o el arte del sonido en el teatro, y en el nacimiento, funcionamiento y cierre de espacios teatrales alternativos madrileños, como fue el caso de La casa de la portera, o de teatros móviles y a domicilio en Santiago de Chile y Miami. También en los Premios Max del año 2016, como "una varilla más del abanico teatral" (p. 244). Romera Castillo reflexiona brevemente sobre el autor y el metateatro (capítulo 11) y enlaza los Premios Max, especialmente la obra La piedra oscura, escrita por Alberto Conejero y dirigida por Pablo Messiez, con el capítulo 14, sobre teatro y homosexualidad, el teatro LGTBIQ, o teatro y marginalismo(s), como se llamó el seminario del SELITEN@T que se celebró del 28 al 30 de junio de 2017, coincidiendo con el World Pride Madrid. En este capítulo, el autor explora las actividades artísticas y teatrales organizadas por el Ayuntamiento y la Comunidad de Madrid durante el evento, así como el Ciclo Iguales en la sala Nave73.

En definitiva, este último volumen de Romera Castillo es un trabajo de gran actualidad, que contiene reflexiones muy personales y poéticas, a juzgar por el último capítulo, y que refleja, aun de manera incompleta, como reconoce el propio autor, los rasgos y el eclecticismo del panorama escénico y teatral actual en España y del teatro español que se representa 
en el resto del mundo, especialmente en lo que concierne a los clásicos. Además de resultar un homenaje al SELITEN@T, su equipo y demás participantes y colaboradores, en la universidad y fuera de ella, es un trabajo que anima a los investigadores del teatro a completar sus investigaciones, a partir de los recursos que se proponen, incluida la Guía del Ocio, sobre aquellas obras de éxito y en la cartelera, y sobre compañías como Teatro del Temple o SeXpeare, por citar algunas de las que se mencionan. De los centenarios al teatro LGTBIQ, Romera Castillo observa el teatro como fenómeno artístico y también como "hecho cultural y social de primera instancia" (p. 150), que debe ser estudiado en un contexto determinado, que nos habla de lo que hay a nuestro alrededor. Se trata de un trabajo optimista, realista, alejado de lo purista, integrador, que reúne los temas más diversos y defiende la vigencia del arte teatral en la actualidad y de cualquier forma que promueva teatro. Mi consejo: léanlo junto con los trabajos en Circuitos teatrales del siglo XXI, de Editorial Antígona.

Susana Inés Pérez 